\title{
Alternative variable refrigerant flow (VRF) air conditioning systems with rational distribution of thermal load
}

\author{
Mykola Radchenko $^{1 *}$, Tadeusz Bohdal ${ }^{2}$, Andrii Radchenko ${ }^{1}$, Eugeniy Trushliakov ${ }^{1}$, Veniamin Tkachenko $^{1}$, Oleksii \\ Zielikov $^{1}$ and Felix Tzaran ${ }^{1}$ \\ ${ }^{1}$ Admiral Makarov National University of Shipbuilding, 9 Heroes of Ukraine Avenue, Mykolayiv, Ukraine \\ ${ }^{2}$ Koszalin University of Technology, 2 Śniadeckich Street, Koszalin 75-453, Poland
}

\begin{abstract}
One of the most attractive reserves of enhancing the energetic efficiency of air conditioning systems (ACS) is to provide operation of compressors in closed to nominal modes by choosing the rational design refrigeration capacities and their distribution according to current thermal loading to provide closed to maximum annual refrigeration energy generation. Generally, the overall thermal load band of any ACS comprises the unstable load range, corresponding to ambient air precooling with significant load fluctuations, and a comparatively stable load part for further air conditioning from a threshold temperature to a target value. The stable thermal load range can be covered by operation of conventional compressor in closed to nominal mode, meantime ambient air precooling needs load modulation by applying a variable speed compressor. A proposed ACS enables a wide range of refrigerant flow variation without heat flux drop in air coolers and can be considered as advanced alternative to variable refrigerant flow systems.
\end{abstract}

\section{Introduction}

The efficiency of ambient air conditioning systems (ACS) performance depends on their loading and a duration of operation all the year round. The higher loading and longer duration of ACS operation during a year, the larger annual refrigeration energy production according to conditioning duties. The rational design refrigeration capacity of ACS has to cover current thermal loads in response to actual ambient air parameters and to provide closed to maximum annual refrigeration production avoiding refrigeration machine (RM) and the whole ACS oversizing. In addition the method of ACS designing should provide rational refrigeration capacity distribution within ambient air processing. Issuing from this the overall thermal load of ACS can be divided into unstable load range, corresponding to ambient air precooling with significant load fluctuations, and a comparatively stable load part for further air conditioning to the target temperature. The unstable thermal load range should be covered through refrigeration capacity regulation, meanwhile the stable range - by operation of the refrigeration compressor practically in nominal mode.

\section{Literature review}

A lot of publications focused to improve the efficiency of ACS by intensification of heat transfer in evaporators [1-3], advanced scheme of ACS [4, 5] and RM [6, 7], vapour ejector [8-10], liquid injector or jet pump [11, 12] and thermopressor [13, 14] technics. Numerous researchers studied the efficiency of ductless Variable Refrigerant Flow (VRF) systems [15, 16]. The multisplit VRF system saved more than 20\% energy compared to a variable air volume (VAV) system [16].

In a number of investigations the air conditioning is considered as one of the technologies for combined cooling, heating and power (CCHP) [17, 18], or trigeneration $[19,20]$. Some innovative technics in engine intake air cooling [21, 22] and waste heat conversion might be implemented in ACS. The heat potential converted in refrigeration can be increased by deep heat utilization [23-25] and application of lowtemperature condensing surface [26, 27]. The absorption lithium-bromide chillers (ACh) are the most widely used and provide cooling air to about $15^{\circ} \mathrm{C}$ with a high coefficient of performance (COP $=0.7-0.8)$ [28]. The most simple ejector chillers (ECh) enables to provide cooling air to $10^{\circ} \mathrm{C}$ but with a low COP of 0.2 to 0.3 and can be applied as a booster stage $[29,30]$.

Modern methods, including ANSIS [31-33], can be used for simulation and optimizing the processes. Some of methodological approaches gained in waste heat recovery refrigeration [34, 35] might be successfully applied in air conditioning to choose design refrigeration capacity to match current cooling demand $[36,37]$. All the typical methods, based on the current or summarized annual refrigeration energy production, issue from the assumption of a design refrigeration capacity to cover maximum conditioning needs over the full range of yearly operating conditions [38-40]. Such approach inevitable leads to considerable ACS oversizing and requires to settle the problem of defining

\footnotetext{
* Corresponding author: nirad50@gmail.com
} 
a correct design refrigeration load excluding overestimation.

Thus, the methods should allow to define a rational design refrigeration capacity issuing from the actual ambient thermal loading to provide closed to maximum annual effect and at the same time rational distribution of refrigeration capacity to provide efficient operation of ACS with considerable deviation of current thermal loads from the rational value without falling the thermal efficiency (heat flux) of air coolers. Moreover, they should make it possible to develop the ACS providing such rational distribution of refrigeration capacity in response to actual loading.

The general problem to be solved needs decision of the following tasks: defining a rational design refrigeration capacity of ACS to provide closed to maximum annual effect without oversizing; rational distribution of refrigeration capacity in response to current thermal loads to avoid falling heat flux in air coolers; development of ACS providing a rational distribution of refrigeration capacity according to actual loading.

The aim of research is to develop the advanced twostage ACS and a novel method of their designing that provides rational refrigeration capacity distribution between unstable and stable thermal load ranges to match the current climatic conditions by refrigerant flow variation without considerable heat flux drop in air coolers and refrigeration machine oversizing to achieve closed to maximum annual refrigeration energy generation according to conditioning duties.

\section{Research methodology}

The efficiency of ACS and their RM performance depends on their loading and time duration $\tau$ of their yearly operation. Therefore, the annual refrigeration energy generated by RM in response to current air conditioning duties is considered as a primary criterion for the choice of a rational design refrigeration capacity of ACS.

The proposed method to determine a rational design refrigeration capacity of ACS and their RM is based on the yearly loading cumulative characteristic of ACS as annual summarized refrigeration energy production dependence on a design refrigeration capacity: $\Sigma\left(Q_{0} \cdot \tau\right)=f\left(Q_{0}\right)$. In order to generalize the results and simplify calculations for any total refrigeration capacities $Q_{0}$, it is convenient to present the refrigeration capacity in relative (specific) values per unit air mass flow rate through the air cooler $\left(G_{a}=1 \mathrm{~kg} / \mathrm{s}\right)$ - as specific refrigeration capacity $q_{0}=Q_{0} / G_{a}, \mathrm{~kW} /(\mathrm{kg} / \mathrm{s})$ or $\mathrm{kJ} / \mathrm{kg}$, and $q_{0}=\xi \cdot c_{m a} \cdot \Delta t_{a}$, where $\Delta t_{a}=\left(t_{a m b}-t_{a 2}\right) ; t_{a m b}-$ ambient air temperature at the inlet of air cooler, $\mathrm{K}$ or ${ }^{\circ} \mathrm{C} ; t_{a 2}$ - air temperature at the air cooler outlet; $\xi$ - relative heat ratio; $c_{m a}$-specific heat of moist air, $\mathrm{kJ} /(\mathrm{kg} \cdot \mathrm{K})$. A specific annual refrigeration energy production $\Sigma\left(q_{0} \cdot \tau\right)=\Sigma\left(\xi_{c_{m a}} \cdot\left(t_{a}-\right.\right.$ $\left.\left.t_{a 2}\right) \cdot \tau \cdot 10^{-3}\right), \mathrm{kJ} \cdot \mathrm{h} / \mathrm{kg}$.

The input data on ambient air temperature $t_{a m b}$ and relative humidity $\varphi_{\text {amb }}$ were used by applying the program "meteomanz" (http://www.meteomanz.com).
According to a developed method the fluctuations of the current refrigeration energy $q_{0} \cdot \tau$ were considered by the rate of its annual increment $\sum\left(q_{0} \cdot \tau\right)$. The rate of annual refrigeration energy increment as its relative value $\sum\left(q_{0} \cdot \tau\right) / q_{0}$, referred to $q_{0}$ over the whole range of $\sum\left(q_{0} \cdot \tau\right)$, is used as an indicator to efficient utilizing a design refrigeration capacity. This is a principally novel approach to ACS designing versus a traditional approach to cover the maximum current thermal duties and maximum annual refrigeration energy accordingly that leads to RM oversizing.

There were two methods developed: the first - by using the annual summarized refrigeration energy dependence on the design refrigeration capacity of the $\mathrm{RM}$ to choose its rational value $q_{0 \text {.rat }}$, that provides closed to maximum annual refrigeration generation $\sum\left(q_{0} \cdot \tau\right)$, and the second - according to the maximum rate of annual refrigeration energy increment $\sum\left(q_{0} \cdot \tau\right) / q_{0}$ to choose optimum design refrigeration capacity $q_{0 . \text { opt }}$, that provides minimum sizes of RM and ACS (Fig. 1,a).
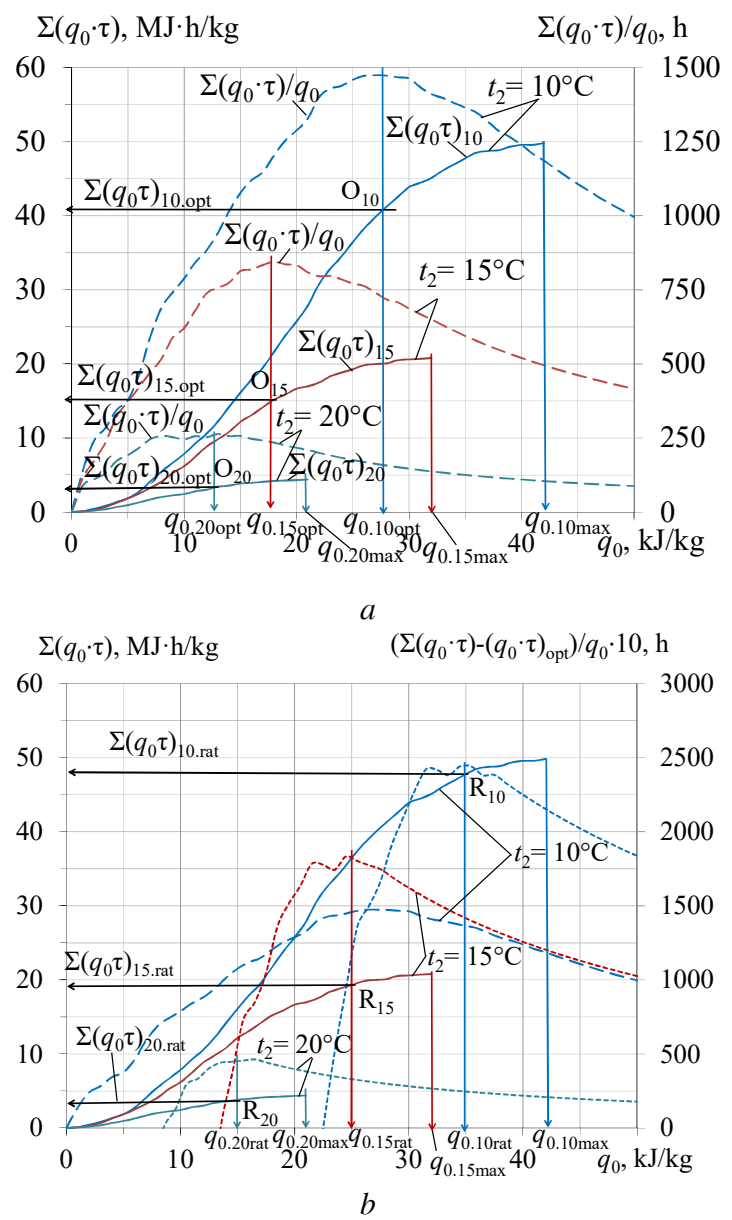

Fig. 1. Specific annual refrigeration energy $\sum\left(q_{0} \cdot \tau\right)$ and its relative values $\sum\left(q_{0} \cdot \tau\right) / \mathrm{q}_{0}$ referred to design specific refrigeration capacity $q_{0}$ over the whole range of $\sum\left(q_{0} \cdot \tau\right)$ (a) and values $\left(\sum\left(q_{0} \cdot \tau\right)-\sum\left(q_{0} \cdot \tau\right)_{\text {opt }}\right) / \mathrm{q}_{0} \cdot$ beyond the optimal values of $\sum\left(q_{0} \cdot \tau\right)_{\text {opt }}$ and $q_{0 . o p t ~}(\mathrm{~b})$ for cooling ambient air to $t_{a 2}=10$, 15 and $20^{\circ} \mathrm{C}$

The rational value of design specific refrigeration capacity $q_{0 \text {.rat }}$, providing a closed to maximum annual refrigeration energy production $\sum\left(q_{0} \cdot \tau\right)$ is associated with the second maximum rate of annual specific refrigeration energy production $\sum\left(q_{0} \cdot \tau\right)$ increment 
within its range beyond the first maximum rate: $q_{0}>q_{0 \text { opt }}$ and $\sum\left(q_{0} \cdot \tau\right)>\sum\left(q_{0} \cdot \tau\right)_{\text {opt }}$ accordingly. With this a relative parameter $\left[\sum\left(q_{0} \cdot \tau\right)-\sum\left(q_{0} \cdot \tau\right)_{\text {opt }}\right] / q_{0}$ is used as indicator to choose a rational value $q_{0 . \text { rat }}$ (Fig. 1b).

The results of calculations of optimum $q 0$ opt and rational $q_{0 . \text { rat }}$ specific refrigeration capacity for $t_{a 2}=10$, 15 and $20{ }^{\circ} \mathrm{C}$ and temperate climatic conditions of Voznesensk, Nikolaev region, southern Ukraine, 2017 year, are presented in Fig. 1. A maximum rate of annual refrigeration energy increment $\sum\left(q_{0} \cdot \tau\right) / q_{0} \cdot$ for $t_{a 2}=10^{\circ} \mathrm{C}$ takes place at the optimal design refrigeration capacity $q_{0 . \text { opt }}$ of $25 \mathrm{~kJ} / \mathrm{kg}$.

A maximum rate of annual refrigeration energy increment $\left(\sum\left(q_{0} \cdot \tau\right)-\sum\left(q_{0} \cdot \tau\right)_{\text {opt }}\right) / q_{0}$ within the range beyond the value $\sum\left(q_{0} \cdot \tau\right)_{\text {opt }}=40 \quad \mathrm{MWh} /(\mathrm{kg} / \mathrm{s})$ corresponding to $q_{0.0 p t}=25 \mathrm{~kJ} / \mathrm{kg}$ takes place at the rational design refrigeration capacity $q_{0 . \mathrm{rat}}=35 \mathrm{~kJ} / \mathrm{kg}$ and provides annual specific refrigeration energy $\sum\left(q_{0} \cdot \tau\right)_{\text {rat }}=49 \mathrm{MJ} \cdot \mathrm{h} / \mathrm{kg}$ that is very closed to its maximum value $50 \mathrm{MJ} \cdot \mathrm{h} / \mathrm{kg}$ but at a design refrigeration capacity $q_{0 . \text { rat }}=35 \mathrm{~kJ} / \mathrm{kg}$ less than $q_{0 . \max }=42 \mathrm{~kW} /(\mathrm{kg} / \mathrm{s})$ by $15 \%$ less.

\section{Results}

The further development of the method of ACS designing consists in rational distribution of the overall design refrigeration capacity between two ranges. The ambient air processing is considered as a two-stage one and includes a fluctuation range as the high-temperature and stable range as the low-temperature stage (Fig. 2).

The values of specific refrigeration capacity $q_{0.15}$, needed for conditioning ambient to $t_{a 2}=15^{\circ} \mathrm{C}$, and $q_{0.10}$, needed for conditioning ambient air to $t_{a 2}=10^{\circ} \mathrm{C}$, and the specific refrigeration capacity $q_{0.10-15}$ as their difference $q_{0.10-15}=q_{0.10}-q_{0.15}$, needed for cooling air from $t_{a 2}=15^{\circ} \mathrm{C}$ to $t_{a 2}=10^{\circ} \mathrm{C}$, is calculated for climatic conditions in Voznesensk, Nikolaev region in July 2017 (Fig. 2).

As Fig. 2 shows, with conditioning the ambient air to $t_{a 2}=15^{\circ} \mathrm{C}$ the fluctuations of the current thermal load $q_{0.15}$ are gradual, that points out that if a design maximum current thermal load is chosen, this results in a significant excessive refrigeration capacity in the temperate daily hours.

At the same time, when air is cooled from $t_{a 2}=15^{\circ} \mathrm{C}$ to $t_{a 2}=10^{\circ} \mathrm{C}$, the fluctuations in the thermal load $q_{0.10-}$ ${ }_{15}=q_{0.10}-q_{0.15}$ are comparatively small: within $10 \mathrm{~kJ} / \mathrm{kg}$.

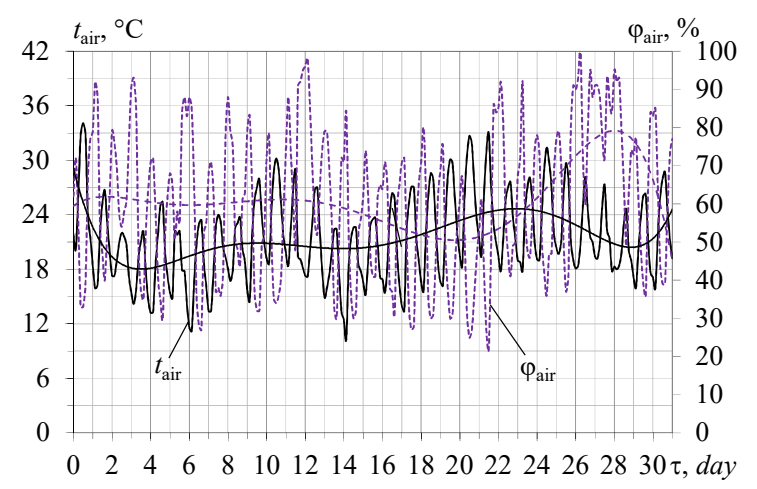

$a$

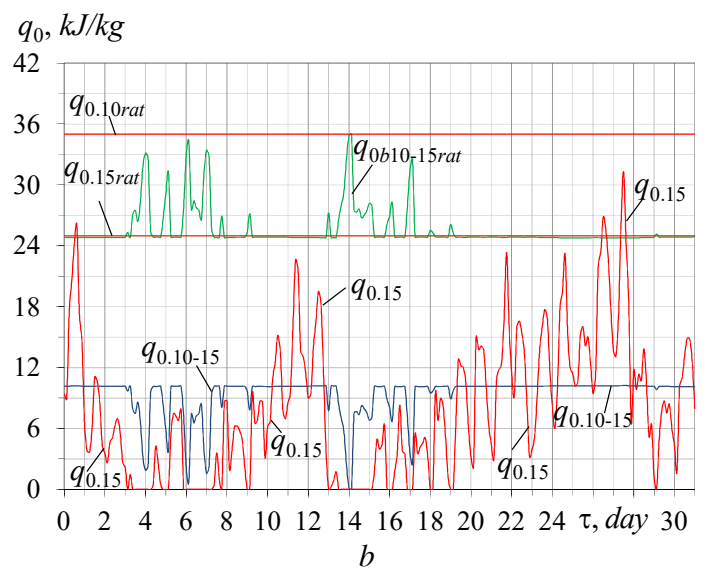

Fig. 2. Current values of ambient air temperature $t_{a}$ and relative humidity $\varphi_{a}(\mathrm{a})$, rational design specific refrigeration capacities $q_{0.15 \text { rat }}$ and $q_{0.10 \text { rat }}$ refrigeration capacity $q_{0.15}$ needed for cooling ambient air to $t_{a 2}=15^{\circ} \mathrm{C}$, refrigeration capacity $q_{0.10-15}=q_{0.10}-q_{0.15}$ for cooling air from $t_{a 2}=15^{\circ} \mathrm{C}$ to $t_{a 2}=10^{\circ} \mathrm{C}$ and available boost refrigeration capacity $q_{0 . \mathrm{b} 10-15}(\mathrm{~b})$.

The temperature of cooled air $t_{a 2}=15^{\circ} \mathrm{C}$ is reasonably to use as the threshold value to shear the overall design thermal load into a comparatively stable load range $q_{0.10-15}$ and the unstable range of ambient air precooling.

So, the stable load value $q_{0.10-15}$ is chosen as design basic stable part $q_{0.10-15}=q_{0.10}-q_{0.15}$ of the rational refrigeration capacity $q_{0.10 \text { rat }}=35 \mathrm{~kJ} / \mathrm{kg}$ (Fig. 1). Accordingly, the remaining part of q0.10rat can be used for precooling the air to $t_{a 2}=15^{\circ} \mathrm{C}$ and determined as boost specific refrigeration capacity $q_{0.610-15 \text { rat }}=35-q_{0.10-15}$ (Fig. 2, b).

The unstable $q_{0.15}$ and stable $q_{0.10-15}$ thermal load ranges can be covered by applying variable speed compressors and conventional compressors accordingly.

As Fig. 2, b shows, the available boost refrigeration capacity $q^{0 . b 10-15 r a t}$ generally covers current thermal loads $q_{0.15}$ for precooling ambient air to $t_{a 2}=15^{\circ} \mathrm{C}$. Furthermore, even more less available boost refrigeration capacity q0.b10-20rat also covers the current loads q0.15 except quite short periods of daylight hours (Fig. 3).

There are corresponding correlations used:

$\Delta\left(q_{0.20 \mathrm{rat}} \tau\right)_{\mathrm{exc}}=q_{0.20 \mathrm{rat}} \tau-q_{0.15} \tau ; \Delta\left(q_{0.20 \mathrm{rat}} \tau\right)_{\mathrm{def}}=$ $q_{0.15} \tau-q_{0.20 \mathrm{pau}} \tau ; \Delta \sum\left(q_{0.20 \mathrm{rat}} \tau\right)_{\text {exc }}=\sum\left(q_{0.20 \mathrm{rat}}-q_{0.15}\right) \tau$.

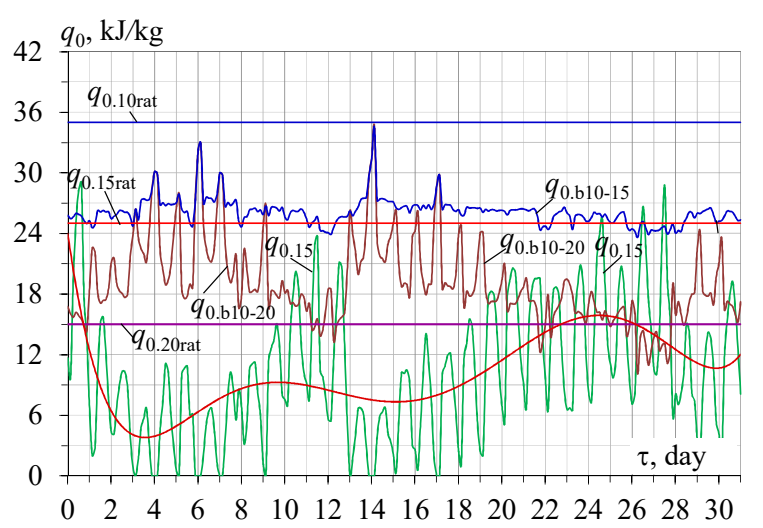

$a$ 


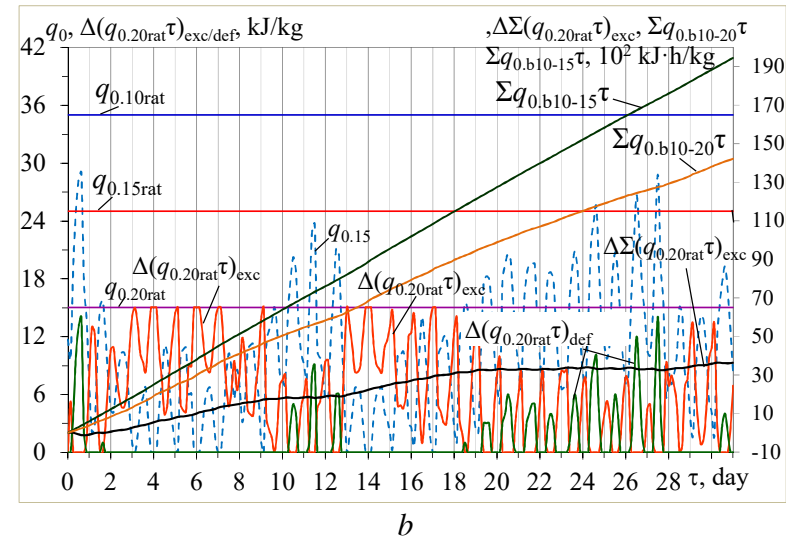

Fig. 3. Current values of available boost specific refrigeration capacity $q_{0.610-20}$ and thermal load $q_{0.15}$ for cooling ambient air to $t_{a 2}=15^{\circ} \mathrm{C}(\boldsymbol{a})$ excess of available refrigeration energy $\Delta\left(q_{0.20 \text { rat }} \tau\right)$ exc over required $q_{0.15}$ and its deficit $\Delta\left(q_{0.20 \text { rat }} \tau\right)_{\text {def }}$, summarized their differences (excess) $\Delta \sum\left(q_{0.20 \text { rat } \tau} \tau\right)$ exc , refrigeration energy due to boost stages $\Sigma q_{0 . b 10-15} \tau$ and $\Sigma q_{0 . b 10-20} \tau$ for $t_{a 2}=15{ }^{\circ} \mathrm{C}$ and $20^{\circ} \mathrm{C}(\boldsymbol{b})$, rational design specific refrigeration capacities $q_{0.10 \text { rat, }}$ $q_{0.15 \text { rat }}$ and $q_{0.20 \text { rat }}$.

As Fig. 3, $a$ testifies, the available excess of design refrigeration capacity $q_{0.20 \text { rat }}$ is enough for deeper cooling air to $t_{a 2}=15^{\circ} \mathrm{C}$ through using the accumulated excessive refrigeration energy $\Delta\left(q_{0.20 \text { rat-15 }} \tau\right)_{\text {exc }}$ to cover its deficit $\Delta\left(q_{0.20 \mathrm{rat}-15} \tau\right)_{\text {def }}$. This statement is also approved by the continuously arising curve of the summarized excess of available design refrigeration energy over its current deficit

$\Delta \sum\left(q_{0.20 \text { rat }-15} \tau\right)_{\text {exc }}=\sum\left(q_{0.20 \text { rat }}-q_{0.15}\right) \tau$ (Fig. 3, b).

As Fig. 3, b shows, the current values of refrigeration energy deficit $\Delta\left(q_{0.20 \mathrm{rat}-15} \tau\right)_{\mathrm{def}}$ to be covered by the excess $\Delta\left(q_{0.20 \text { rat-15 }} \tau\right)_{\text {exc }}$ takes place within the range of thermal load of about $0.5 q_{0.20 \text { rat }}$, i.e. from 7 to $8 \mathrm{~kJ} / \mathrm{kg}$.

Thus, in July the current refrigeration energy deficit can be covered by the accumulated refrigeration excess with the maximum deviation of current load $q_{0}$ of about $7.5 \mathrm{~kJ} / \mathrm{kg}$ from the rational design value $q_{0.20 \mathrm{rat}}=15 \mathrm{~kJ} / \mathrm{kg}(50 \%)$ with corresponding refrigerant flow variation in boost $\mathrm{AC}$. The excessive refrigeration energy as liquid refrigerant can be accumulated in linear receiver and liquid separator in ACS of VRF type (Fig.4).

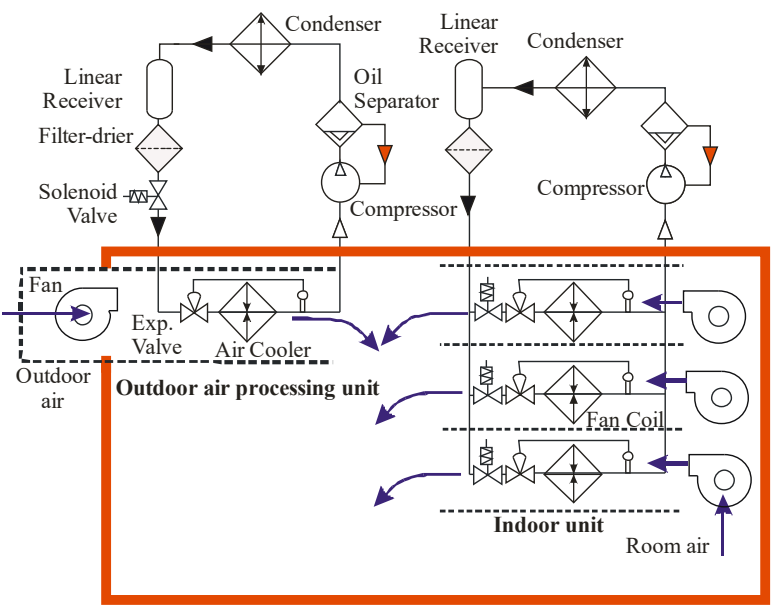

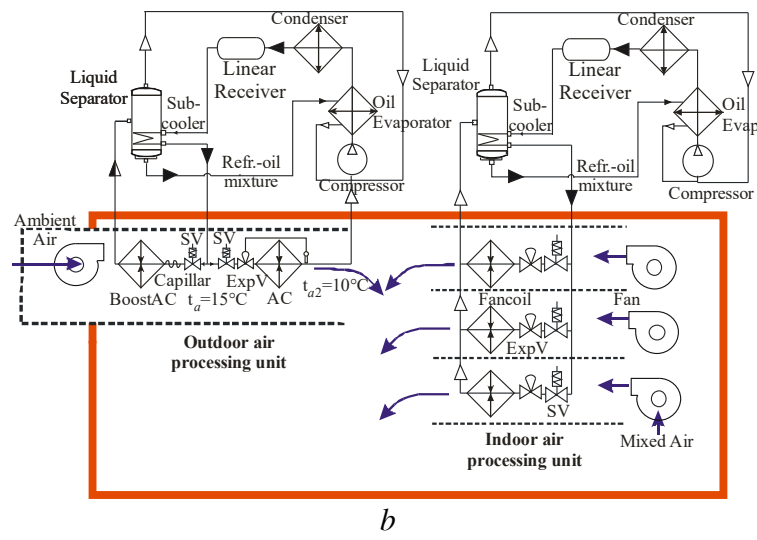

Fig. 4. The scheme of combined outdoor and indoor ACS of VRF type (a) and advanced two-stage central ACS as the outdoor air processing subsystem (b).

Underground for intensification of heat transfer of refrigerant boiling in $\mathrm{AC}$ coils and a larger deviation of refrigerant flows from their optimum values according to current thermal load variations enabled due to refrigerant incomplete evaporation through overfilling the coils is quite evident from the results of calculations (Fig. 5).

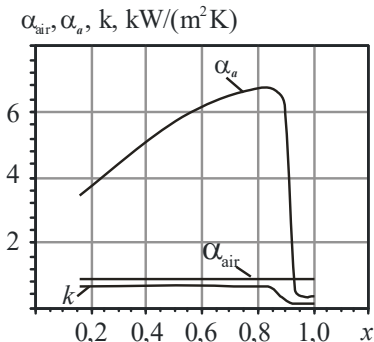

$a$

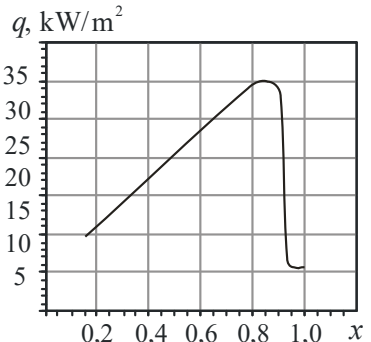

b

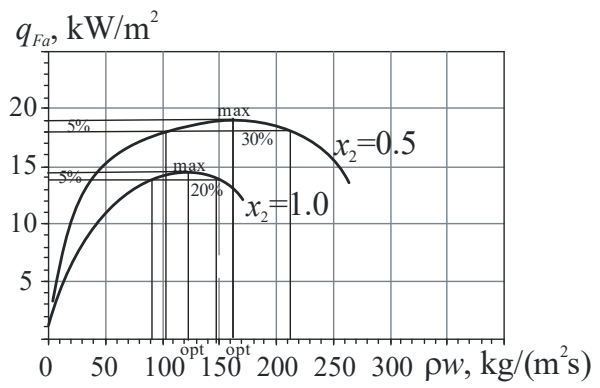

$c$

Fig. 5. Variations of heat transfer coefficients to boiling refrigerant $\alpha_{a}$ and to air $\alpha_{\text {air }}$ and overall heat transfer coefficient $\mathrm{k}$ (a) and heat flux $q_{F a}$ with vapour mass fraction $x_{2}$ (b) and with refrigerant mass velocities $\rho w$ (c).

The convective evaporation of refrigerant in coils is characterized by sharp drop in intensity of heat transfer $\alpha_{a}$ at the final stage of evaporation when burnout takes place. This occurs because of wall surface drying out with transition of refrigerant two-phase flow from annular to disperse flow and leads to decrease in the overall heat transfer coefficient (Fig. 5, a) and heat flux (Fig.5, b). Calculations were conducted for the air cooler with plate finned tubes of 12 and $10 \mathrm{~mm}$ outside and inside diameters, air temperature at the inlet $25^{\circ} \mathrm{C}$ and outlet $15^{\circ} \mathrm{C}$, refrigerant boiling temperature at the exit $0{ }^{\circ} \mathrm{C}$, refrigerant $\mathrm{R} 134$. 
As Fig. 5, c shows, the overfilling the $\mathrm{AC}$ by refrigerant provides an increase in heat flux $q_{F a}$ by 25 to $40 \%$ compared with conventional complete refrigerant evaporation and enables a larger deviation of refrigerant mass velocities $\rho w$ from their optimum value, providing maximum value of heat flux $q_{F a}$, that means that a larger thermal load changes $(30 \%$ and more) are permitted. This gives good perspectives of the application of developed two-stage ACS with incomplete refrigerant boiling in the $\mathrm{AC}$ as the $\mathrm{ASC}$ with refrigerant flow self-regulation (Fig. 4, b) and alternative to VRF systems. The injector liquid refrigerant recirculation in the $\mathrm{AC}$ can be applied as the advanced variant of $\mathrm{AC}$ overfilling.

\section{Conclusions}

A novel trend in air conditioning by two-stage ambient air processing with unstable and stable thermal loads and different refrigerant feeding to air coolers accordingly has been proposed as advanced or alternative to VRF systems.

A novel methodological approach is developed to determine a rational design thermal load on the ACS that provides closed to maximum annual refrigeration energy generation and decrease of installed refrigeration capacity by 15 to $20 \%$.

The method allows to design the ACS with efficient operation at varying loading with minimum oversizing and enlarged deviation of refrigerant flows according current loading from designed value without sensible decreasing heat flux in AC.

A two-stage ACS could be considered as a perspective trend in ACS for space conditioning as well as a subsystem of trigeneration installation. The application of such combined two-stage intake air cooling technologies are especially expedient for operation of ACS in temperate climatic conditions.

\section{References}

1. D. Mikielewicz, M. Klugmann, J. Wajs, International Journal of Thermal Sciences 65, 79 (2013)

2. D. Mikielewicz, Heat Transfer Engineering 37(1314), 1158 (2016)

3. A. Radchenko, E. Trushliakov, K. Kosowski, D. Mikielewicz, M. Radchenko, Energies 13, 6201 (2020)

4. E. Trushliakov, A. Radchenko, M. Radchenko, S. Kantor, O. Zielikov, The Efficiency of refrigeration capacity regulation in the ambient air conditioning system, in Advances in Design, Simulation and Manufacturing III (DSMIE 2020), LNME, pp. 343-353 (2020)

5. M. Radchenko, R. Radchenko, V. Tkachenko, S. Kantor, E. Smolyanoy, Increasing the operation efficiency of railway air conditioning system on the base of its simulation along the route line, in Integrated Computer Technologies in Mechanical
Engineering (ICTM 2019), AISC, 1113, pp. 461467 (2020)

6. E. Trushliakov, A. Radchenko, S. Forduy, A. Zubarev, A. Hrych, Increasing the operation efficiency of air conditioning system for integrated power plant on the base of its monitoring, in Integrated Computer Technologies in Mechanical Engineering (ICTM 2019), AISC, 1113, pp. 351360 (2020)

7. M. Radchenko, D. Mikielewicz, V. Tkachenko, M. Klugmann, A. Andreev, Enhancement of the operation efficiency of the transport air conditioning system, in Advances in Design, Simulation and Manufacturing III (DSMIE 2020), LNME, pp. 332-342 (2020)

8. D. Butrymowicz, J. Gagan, K. Śmierciew, M. Łukaszuk, A. Dudar, A. Pawluczuk, A. Łapiński, A. Kuryłowicz, Investigations of prototype ejection refrigeration system driven by low grade heat, in HTRSE-2018, E3S Web of Conferences 70, 7 p. (2018)

9. K. Smierciew, J. Gagan, D. Butrymowicz, J. Karwacki, Energy and Buildings 80, 260 (2014)

10. M. Radchenko, A. Radchenko, R. Radchenko, S. Kantor, D. Konovalov, V. Kornienko, Proceedings of the Institution of Mechanical Engineers, Part A: Journal of Power and Energy. (2021) ttps://doi.org/10.1177/09576509211045455

11. N.I. Radchenko, International Journal of Refrigeration 8(5), 267 (1985)

12. E. Trushliakov, M. Radchenko, T. Bohdal, R. Radchenko, S. Kantor, An innovative air conditioning system for changeable heat loads, in Advanced Manufacturing Processes, InterPartner2019, LNME, pp. 616-625 (2020)

13. D. Konovalov, H. Kobalava, M. Radchenko, I.C. Scurtu, R. Radchenko, Determination of hydraulic resistance of the aerothermopressor for gas turbine cyclic air cooling, in TE-RE-RD 2020, E3S Web of Conferences, 180, 01012 (2020)

14. D. Konovalov, H. Kobalava, V. Maksymov, R. Radchenko, M. Avdeev, Experimental research of the excessive water injection effect on resistances in the flow part of a low-flow aerothermopressor, in Advances in Design, Simulation and Manufacturing III (DSMIE 2020), LNME, pp. 292-301 (2020)

15. Y. Zhu, X. Jin, Z. Du, X. Fang, B. Fan, Appl. Therm. Eng. 64, 385 (2014)

16. Y.P. Zhou, J.Y. Wu, R.Z. Wang, S. Shiochi, Energy Build. 39, 212 (2007)

17. A. Radchenko, I-C. Scurtu, M. Radchenko, S. Forduy, A. Zubarev, Monitoring the efficiency of cooling air at the inlet of gas engine in integrated energy system. Thermal Science, OnLine-First Issue 00, Pages: 344-344 (2020) https://doi.org/10.2298/TSCI200711344R

18. A. Radchenko, D. Mikielewicz, S. Forduy, M. Radchenko, A. Zubarev, Monitoring the fuel 
efficiency of gas engine in integrated energy system, in Integrated Computer Technologies in Mechanical Engineering (ICTM 2019). AISC, 1113, pp. 361-370 (2020)

19. S. Forduy, A. Radchenko, W. Kuczynski, A. Zubarev, D. Konovalov, Enhancing the fuel efficiency of gas engines in integrated energy system by chilling cyclic air, in Advanced Manufacturing Processes, InterPartner-2019, LNME, pp. 500-509 (2020)

20. A. Radchenko, E. Trushliakov, V. Tkachenko, B. Portnoi, O. Prjadko, Improvement of the refrigeration capacity utilizing for the ambient air conditioning system, in Advanced Manufacturing Processes II, InterPartner 2020, LNME, pp. 714723 (2021)

21. A. Radchenko, N. Radchenko, A. Tsoy, B. Portnoi, S. Kantor, Increasing the efficiency of gas turbine inlet air cooling in actual climatic conditions of Kazakhstan and Ukraine, in AIP Conference Proceedings 2285, 030071 (2020)

22. A. Radchenko, A Stachel, S. Forduy, B. Portnoi, O. Rizun, Analysis of the efficiency of engine inlet air chilling unit with cooling towers, in Advances in Design, Simulation and Manufacturing III (DSMIE 2020), LNME, pp. 322-331 (2020)

23. V. Kornienko, M. Radchenko, R. Radchenko, D. Konovalov, A. Andreev, M. Pyrysunko. Improving the efficiency of heat recovery circuits of cogeneration plants with combustion of waterfuel emulsions. Thermal Science 25 (1 Part B), 791-800 (2021)

24. V. Kornienko, R. Radchenko, D. Konovalov, A. Andreev, M. Pyrysunko. Characteristics of the rotary cup atomizer used as afterburning installation in exhaust gas boiler flue, in Advances in Design, Simulation and Manufacturing III (DSMIE 2020). LNME, pp. 302-311 (2020)

25. V. Kornienko, R. Radchenko, D. Mikielewicz, M. Pyrysunko, A. Andreev. Improvement of characteristics of water-fuel rotary cup atomizer in a boiler, in Advanced Manufacturing Processes. InterPartner-2020. LNME, pp. 664-674 (2021)

26. V. Kornienko, R. Radchenko, Ł. Bohdal, L. Kukiełka, S. Legutko, Investigation of condensing heating surfaces with reduced corrosion of boilers with water-fuel emulsion combustion, in Integrated Computer Technologies in Mechanical Engineering (ICTM 2020), LNNS, 188, pp. 300309 (2021)

27. M. Radchenko, R. Radchenko, V. Kornienko, M. Pyrysunko, Semi-empirical correlations of pollution processes on the condensation surfaces of exhaust gas boilers with water-fuel emulsion combustion, in Advances in Design, Simulation and Manufacturing II (DSMIE 2019), LNME, pp. 853-862 (2020)

28. R. Radchenko, N. Radchenko, A. Tsoy, S. Forduy, A. Zybarev, I. Kalinichenko, Utilizing the heat of gas module by an absorption lithium-bromide chiller with an ejector booster stage, in AIP Conference Proceedings 2285, 030084 (2020)

29. R. Radchenko, M. Pyrysunko, V. Kornienko, I.-C. Scurtu, R. Patyk, Improving the ecological and energy efficiency of internal combustion engines by ejector chiller using recirculation gas heat, in Integrated Computer Technologies in Mechanical Engineering (ICTM 2020), LNNS, 188, pp. 531541 (2021)

30. R. Radchenko, M. Pyrysunko, A. Radchenko, A. Andreev, V. Kornienko, Ship engine intake air cooling by ejector chiller using recirculation gas heat, in Advanced Manufacturing Processes, InterPartner-2020. LNME, pp. 734-743 (2021)

31. L. Bohdal, L. Kukiełka, S. Legutko, R. Patyk, A.M. Radchenko, Materials 13, 3175 (2020)

32. L. Bohdal, L. Kukielka, S. Świłło, A.M. Radchenko, A. Kułakowska, Modelling and experimental analysis of shear-slitting process of light metal alloys using FEM, SPH and visionbased methods, in AIP Conference Proceedings 2078, 020060 (2019)

33. L. Bohdal, L. Kukielka, A.M. Radchenko, R. Patyk, M. Kułakowski, J. Chodór, Modelling of guillotining process of grain oriented silicon steel using FEM, in AIP Conference Proceedings 2078, 020080 (2019)

34. J. Ortiga, J.C. Bruno, A. Coronas, Applied Thermal Engineering 50, 1536 (2013)

35. P.A. Rodriguez-Aumente, M.C. RodriguezHidalgo, J.I. Nogueira, A. Lecuona, M.C. Venegas, Applied Thermal Engineering 50, 1496 (2013)

36. N. Radchenko, A. Radchenko, A. Tsoy, D. Mikielewicz, S. Kantor, V. Tkachenko, Improving the efficiency of railway conditioners in actual climatic conditions of operation, in AIP Conference Proceedings 2285, 030072 (2020)

37. N. Radchenko, E. Trushliakov, A. Radchenko, A. Tsoy, O. Shchesiuk, Methods to determine a design cooling capacity of ambient air conditioning systems in climatic conditions of Ukraine and Kazakhstan, in AIP Conference Proceedings 2285, 030074 (2020)

38. A. Canova, C. Cavallero, F. Freschi, L. Giaccone, M. Repetto, M. Tartaglia, IEEE Industry Applications Magazine 15, 62 (2009)

39. J.L. Forsyth, in: IGT International Liquefied Natural Gas Conference Proceedings 3, 1763 (2013)

40. S.B. Kalhori, H. Rabiei, Z. Mansoori, Energy Conversion and Management 60, 106 (2012) 